\title{
ANALISIS PENGARUH KUALITAS PELAYANAN TELLER TERHADAP KEPUASAN ANGGOTA PADA BMT POLIDANA POLITEKNIK NEGERI SEMARANG
}

\author{
ARIS SUNINDYO \\ Politeknik Negeri Semarang \\ arissunindy0123@gmail.com
}

\begin{abstract}
This study aims to examine the quality of teller service which consists of tangibles, reliability, responsiveness, assurance, and empathy of member satisfaction by saving at Baitul Maal Wat Tamwil (BMT) Polidana Semarang State Polytechnic. The data used are primary data in the form of questionnaires' distribution to BMT members. The data used are primary data which are distributed through questionnaires to BMT members. This study used 100 members of the BMT Polidana as a sample. The data analysis tool used multiple regression analysis with SPSS 21 . The results showed that tangibles, reliability, responsiveness and assurance had a significant effect on member satisfaction in saving at BMT Polidana State Polytechnic Semarang while empathy (empathy) does not have a significant effect on member satisfaction in saving at BMT Polidana Semarang State Polytechnic
\end{abstract}

Keywords: Service Quality, Customer Satisfaction

Abstrak: Penelitian ini bertujuan untuk menguji kualitas pelayanan teller yang terdiri dari tangibles (bukti fisik), reliability (keandalan), responsiveness (daya tanggap), assurance (jaminan), dan empathy (empati) terhadap kepuasan anggota dalam menabung pada Baitul Maal Wat Tamwil (BMT) Polidana Politeknik Negeri Semarang. Data yang digunakan adalah data primer yang didisitribusikan melalui kuesioner kepada para anggota BMT. Penelitian ini menggunakan 100 orang anggota BMT Polidana sebagai sampel. Alat analisis data menggunakan analisis regresi berganda dengan bantuan SPSS 21. Hasil penelitian menunjukkan bahwa tangibles (bukti fisik), reliability (keandalan), responsiveness (daya tanggap), assurance (jaminan) memiliki pengaruh yang signifikan, sedangkan empathy (empati) tidak memilki berpengaruh signifikan terhadap kepuasan anggota dalam menabung pada BMT Polidana Politeknik Negeri Semarang.

Kata kunci: Kualitas Pelayanan, Kepuasan Nasabah

\section{Pendahuluan}

Persaingan usaha yang semakin bergejolak pada era seperti yang terjadi sekarang ini, membuat unit usaha harus lebih kritis dan inovatif dalam mengembangakan produk untuk dapat memberikan service excellent kepada pelanggannya sehingga perusahaan memilki nilai lebih dimata pelanggannya. Baitul Maal Wat Tamwil (BMT) selaku mitra masyarakat yang berperan dalam menyediakan layanan keuangan masyarakat, dituntut untuk semakin mengoptimalkan kualitas pelayanan kepada anggota dengan sebaik-baiknya agar kepuasan anggota tetap terjaga terkait pelayanan keuangan. Menurut Kasmir (2007:15) pelayanan yang baik akan memberikan kepuasan kepada anggota. Pelayanan yang baik akan menentukan kualitas pada produk atau jasa sebagai tuntutan bagi perusahaan jasa seperti BMT, sehingga BMT dituntut untuk dapat memberikan pelayanan terbaik kepada para anggotanya. Untuk dapat menjaga kepuasan anggota, BMT berusaha untuk memenuhi kebutuhan para anggota dengan produk yang dimilikinya. Kotler dalam Rangkuti (2002:23) menyatakan kepuasan pelanggan adalah a person's feeling of pleasure of disappoinment resulting from 
comparing a product's received performance (or outcome) in relations to the person's expectation, sehingga dapat diartikan sebagai perasaan senang atau kecewa atas hasil antara prestasi atau produk yang dirasakan dan diharapkannya. Saat ini anggota BMT memiliki harapan yang tinggi atas setiap produk atau jasa yang ditawarkan. Mereka berharap BMT dapat merealisasikan apa yang dinginkan dan butuhkan oleh semua anggota. Hal tersebut mendorong manajemen BMT untuk mengevaluasi kembali tingkat kualitas pelayanan dalam melayani anggotanya selama ini.

Dalam menjaga kualitas pelayanan kepada para anggota, pelayanan prima menjadi tuntutan garda terdepan yakni frontliner (teller) sebagai bagian yang langsung berinteraksi dalam memperkenalkan produk dan jasanya kepada anggota. Kepuasan anggota sendiri merupakan prioritas pertama bagi seluruh organisasi selaku lembaga yang bergerak di bidang pelayanan dan jasa. Agar mendapatkan kepercayaan dari para anggotanya, perusahaan harus menjadikan kepuasan anggota sebagai fondasi utama, yaitu dengan memberikan pelayanan yang prima. Pelayanan yang prima dilakukan dengan memberikan segala kebutuhan yang diperlukan oleh anggota sehingga mereka merasa segala kebutuhannya terpenuhi dan memiliki kepuasan atas pelayanan yang diberikan. Hal tersebut dapat direalisasikan melalui pendekatan pelayanan yang dapat dirasakan secara langsung kepada pelanggan sehingga membawa pengaruh positif dan signfikan antara tingkat kualitas pelayanan yang diberikan dengan tingkat kepuasan pelanggan, kenaikan tingkat kualitas pelayanan yang diberikan oleh lembaga akan berdampak pada kenaikan tingkat kepuasan yang dirasakan anggota (Panjaitan dan Yuliati, 2016).

Banyaknya upaya yang dilakukan agar dapat tetap eksis di masa krisis seperti saat ini, yakni dengan menghadapi persaingan yang dirasakan oleh dunia usaha perbankan lainnya. Salah satu cara yang harus dijalani organisasi perbankkan saat ini dengan menentukan langkah strategi yang tepat agar tetap dapat eksis dengan meningkatkan laba organisasi di tengah persaingan usaha. Namun dalam menjalankan strateginya, banyak perusahaan yang mengalami pasang surut usahanya tanpa didukung oleh teamwork untuk menghasilkan kinerja perusahaan perbankan yang baik (Lumempow dkk., 2015). Seluruh bagian memegang peranan penting dalam mendukung kinerja organisasi tanpa terkecuali frontliner yakni teller. Selain memenuhi kebutuhan anggota, tugas dari teller yaitu harus berupaya untuk selalu berhubungan baik dengan anggota. Hubungan yang baik akan memberikan kesan yang baik pada BMT. Berdasarkan hal tersebut, penilaian baik dari anggota dapat terus meningkatkan citra dari BMT itu sendiri. Teller diharapkan memiliki skill dalam berkomunikasi dengan baik pada BMT, melayani anggota dengan prosedur yang tepat, respon pelayanan yang tanggap, dan sebagai pemberi informasi yang lengkap. Dalam melayani anggota, teller juga harus difasilitasi untuk menunjang kinerjanya baik sarana maupun prasarana. Seorang teller service harus memiliki kemampuan dalam menerapkan dasar-dasar pelayanan untuk memuaskan anggota, antara lain pemahaman kebutuhan anggota, pengenalan produk dan jasa yang diberikan, penjelasan informasi yang akurat, dan lain sebagainya. Sebagai teller, pelayanan yang berkualitas sangat diinginkan oleh anggota. Pengetahuan tentang dasar-dasar pelayanan dan segala sesuatu tentang organisasi dan produk yang ditawarkan harus dikuasai oleh seorang teller agar pelayanan yang berkulitas tersebut dapat tercipta pada lembaga yang bergerak dibidang pelayanan.

BMT yang merupakan lembaga yang bergerak di bidang pelayanan dan diharapkan mampu memenuhi kebutuhan pelanggan baik pihak internal maupun eksternal. Definisi lain BMT merupakan lembaga keuangan mikro yang beroperasi berdasarkan prinsip pembagian keuntungan, mengembangakan usaha skala mikro, untuk meningkatkan kesejahteraan pelaku ekonomi (Guru Ekonomi, 2020). Penyebutan lain Baitul Maal Wat Tamwil adalah salah satu jenis koperasi simpan pinjam pembiayaan syariah yang dikenal melayani unit bisnis skala mikro maupun menengah yang berlokasi dengan domisili terdekat. Jasa yang diberikan oleh BMT memiliki ruang lingkup yang terbatas 
dibanding perbankkan yang jauh memiliki produk perbankkan yang lebih luas dan banyak (Kasmir, 2007:19).

BMT Polidana berkedudukan di jurusan Akuntansi Politeknik Negeri Semarang. Pertumbuhan BMT Polidana juga mengalami kemajuan kinerja yang dapat dilihat dari peningkatan aset dari tahun ketahun yang terus mengalami kenaikan yang dapat dilihat pada tabel dibawah ini yakni tabel 1.

Tabel 1 Jumlah Aset Tahun 2016-2019

\begin{tabular}{cc}
\hline Tahun & Jumlah Aset \\
\hline 2016 & Rp 5.498.784.292 \\
2017 & Rp 6.735.174.014 \\
2018 & Rp 8.848.743.036 \\
2019 & Rp 12.514.082.903
\end{tabular}

Sumber: Profil BMT Polidana Politeknik Negeri Semarang

Hal ini menunjukkan bahwa pelayanan frontliner yakni teller dalam melayani anggota sangat baik, terlihat dari peningkatan aset yang terus mengalami peningkatan. Selain itu, peningkatan simpanan sukarela juga mengalami kenaikan sesuai dengan data yang ditunjukkan pada tabel dibawah ini yakni tabel 2.

Tabel 2 Kenaikan Jumlah Simpanan Sukarela 2016-2019

\begin{tabular}{cc} 
Tahun & Simpanan Sukarela \\
\hline 2016 & Rp 3.528.936.586 \\
2017 & Rp 4.303.701.873 \\
2018 & Rp 5.151.451.701 \\
2019 & Rp 7.327.330.573 \\
\hline
\end{tabular}

Sumber: Profil BMT Polidana Politeknik Negeri Semarang

Meningkatnya kualitas layanan yang diberikan oleh BMT khususnya frontliner yakni teller akan meningkatkan kepuasan anggotan dengan bentuk kepercayaan untuk menempatkan dananya melalui BMT Polidana. Mengingat pentingnya kepuasan pelanggan, maka BMT khususnya bagian frontliner selalu berupaya melakukan peningkatan kinerja untuk terus meningkatkan kualitas layanan BMT Polidana. Kualitas pelayanan organisasi merupakan hal utama yang mampu memberikan tingkat kepuasan kepada anggotanya yang dapat dilakukan secara tertulis maupun tidak tertulis (Yaves et al, 2004 dalam Sulistyawati dan Seminari, 2015). Daalm mengukur kualitas layanan faktor yang digunakan antara lain menggunakan tangibles, reliability, responsiveness, assurance, dan empathy (Puung dkk., 2014).

Hasil penelitian beberapa peneliti yang menggunakan faktor dalam mengukur kualitas layanan yang diadopsi oleh Puung dkk., (2014) menunjukkan hasil yang berbeda beda. Hasil penelitian Wiharsih dan Efendi (2014), menunjukkan bahwa variabel reliability, responsiveness, dan tangible tidak berpengaruh sedangkan variabel assurance dan empathy bepengaruh terhadap customer satisfaction. Hasil penelitian Yulianti (2013) menunjukkan bahwa reliability, responsiveness, assurance, empathy, dan tangibles mempengaruhi tingkat kepuasan nasabah dalam meletakkan dananya pada lembaga keuangan. Penelitian Wiyanto (2016), menunjukkan hasil bahwa variabel reliability, responsiveness dan empathy berpengaruh pada kepuasan baik nasabah tingkat atas maupun menengah pada BSM cabang Salatiga, namun lain halnya dengan variabel tangible dan assurance tidak menunjukkan pengaruh. Hasil penelitian Koesasi dan Latief (2017), menunjukkan bahwa tingkat kepuasan dipengaruhi oleh kehandalan, ketanggapan, jaminan, dan bukti fisik sedangkan variabel empati tidak berpengaruh signifikan terhadap tingkat kepuasan lembaga keuangan di Balikpapan. Penelitian Kuswanto (2009), menunjukkan bahwa tangible dan empathy memiliki pengaruh pada tingkat kepuasan nasabah, 
sedangkan reliability dan responsiveness tidak memiliki pengaruh. Lumempow dkk. (2015) hasil penelitiannya menunjukkan bahwa tangibles, reliability, assurance, empathy memliki pengaruh signifikan terhadap kepuasan nasabah, sedangkan responsiveness tidak berdampak terhadap kepuasan nasabah.

Mengingat BMT Polidana Politeknik Negeri Semarang merupakan BMT yang relatif baru dan sedang mengalami perkembangan, sehingga perlu masukan dalam rangka peningkatan kualitas layanan khususnya bagian frontliner yakni teller. Penelitian ini dilakukan dengan tujuan menguji pengaruh kualitas pelayanan teller dengan menggunakan faktor faktor antara lain tangibles, reliability, responsiveness, assurance, dan empathy terhadap kepuasan anggota dalam menabung pada BMT Polidana Politeknik Negeri Semarang.

Berdasarkan hasil penelitian terdahulu, dalam rangka menghasilkan pelayanan yang berkualitas maka bagian frontliner khususnya teller akan memperhatikan ruang lingkup pekerjaannya mulai dari bukti fisik bisa dalam bentuk berpenampilan menarik, kerapihan ruang kerja dan layanan, sikap dan perilaku yang ramah saat melayani, kecermatan dan ketelitian serta tanggung jawab dalam bekerja akan memberikan jaminan yang terbaik dalam melayani anggota yang memerlukan informasi atau bantuan layanan BMT sehingga akan timbul rasa empathy. Hal tersebut akan menambah tingkat kepuasan anggotan BMT sehingga Anggota akan menjaga loyalitasnya sebagai nasabah BMT. Kerangka pemikiran dalam penelitian ini tertuang dalam gambar 1.

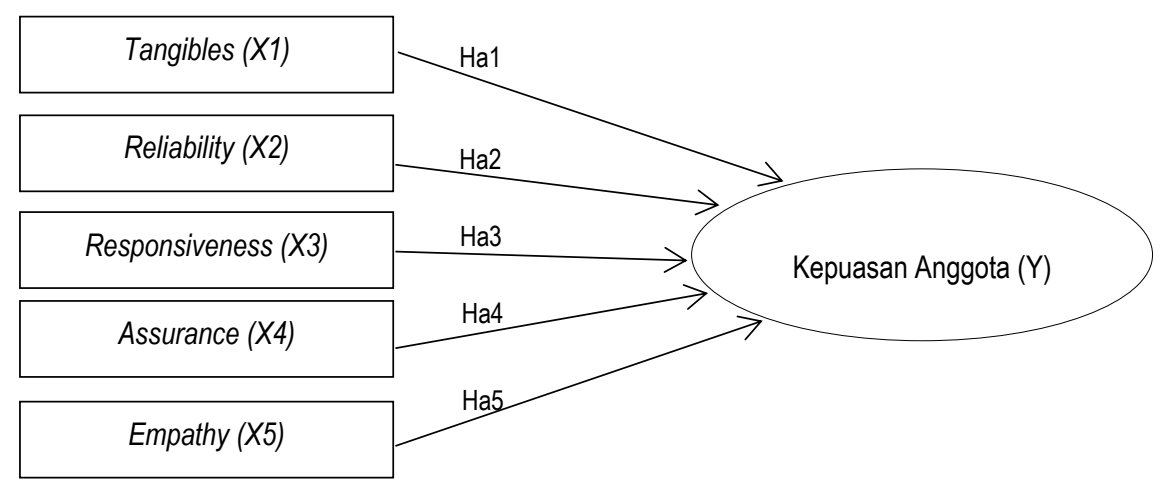

Gambar 1 Kerangka Penelitian

Berdasarkan kerangka penelitian diatas, maka tingkat kualitas layanan teller diduga memiliki dampak pada kepuasan anggota, sehingga hipotesis yang diajukan dalam penelitian ini adalah sebagai berikut :

Ha1: Variabel Tangibles berpengaruh signifikan terhadap kepuasan anggota dalam menabung pada BMT Polidana Politeknik Negeri Semarang

Ha2: Variabel Reliability berpengaruh signifikan terhadap kepuasan anggota dalam menabung pada BMT Polidana Politeknik Negeri Semarang.

Ha3: Variabel Responsiveness berpengaruh signifikan terhadap kepuasan anggota dalam menabung pada BMT Polidana Politeknik Negeri Semarang.

Ha4: Variabel Assurance berpengaruh signifikan terhadap kepuasan anggota dalam menabung pada BMT Polidana Politeknik Negeri Semarang.

Ha5: Variabel Empathy berpengaruh signifikan terhadap kepuasan anggota dalam menabung pada BMT Polidana Politeknik Negeri Semarang. 


\section{Metode Penelitian}

Penelitian ini akan melihat adanya pengaruh sebab akibat antara variabel kualitas layanan dengan variabel kepuasan nasabah (Sugiyono (2012:37). Data penelitian ini merupakan data primer, dan pengumpulannya dilakukan dengan menggunakan kuesioner yang disebarkan kepada anggota BMT, selain itu penulis juga melakukan observasi, wawancara langsung kepada anggota dan melakukan studi kepustakaan dalam menambah literatur penelitian ini.

Penelitian ini menggunakan metode analisis data dengan beberapa tahapan pengujian antara lain pengujian kualitas data, pengujian asumsi klasik dan pengujian hipotesis. Kriteria pengujian bila croanbach alpha diatas 0,60 dikatakan reliabel, sedangkan bila nilai $R$ tabel lebih rendah dari nilai $R$ hitung dinyatakan valid. Kriteria uji asumsi klasik, bebas multiko bila memiliki nilai variance inflation factor (VIF) < dari 10 dan mempunyai tolerance $>0,10$. Nilai Kolmogorov-Smirnov $>0,05$ maka data dikatakan normal. Durbin-Watson (DW test) untuk mengetahui ada atau tidaknya autokorelasi. Pengujian heteroskedastisitas dengan melihat apakah titik tersebut membentuk pola tertentu atau tidak (Ghozali, 2018). Pengujian hipotesis yang akan dilakukan dalam penelitian ini adalah Koefisien Determinasi, Pengujian Statistik t (parsial) dan Pengujian Statistik F (simultan) dengan melihat nilai signifikansi.

Dalam penelitian ini definisi operasional variabel yang akan diterapkan adalah kepuasan anggota dan kualitas layanan yang menggunakan 5 dimensi antara lain :

1. $X_{1}$. Tangible yaitu penampilan fisik, furniture, pegawai yang bekerja, dan pemasangan perlengkapan ruangan. Variabel menggunakan instrumen yang digunakan oleh Wiharsih dan Efendi (2014), Darwin dan Kunto (2014), Wiyanto (2016) dan telah disesuaikan dengan subjek penelitian saat ini. Pengukuran memakai skala likert dengan poin 1-4. Indikator dalam variabel ini antara lain ketersediaan fasilitas yang memadai (ruang tunggu, area parkir, toilet dsb), penampilan para karyawan baik dan rapi, suasana ruangan nyaman dan tentram, dan ketersediaan sumber informasi memadai.

2. $\mathrm{X}_{2}$. Reliability yaitu kemampuan pegawai yakni teller dalam memberikan jasa yang dijanjikan kepada nasabah dengan up to date dan tepat. Variabel menggunakan instrumen yang digunakan oleh Darwin dan Kunto (2014), Wiyanto (2016), Koesasi dan Latief (2017) yang disesuaikan dengan subjek penelitian saat ini. Pengukuran menggunakan skala likert dengan poin 1-4. Indikator yang digunakan antara lain kemampuan melayani dengan akurat dan terpercaya, kemampuan dalam problem solving nasabah, dan ketepatan penyediaan informasi.

3. $\mathrm{X}_{3}$. Responsiveness merupakan kemampuan pegawai yakni teller untuk membantu pelanggan dan menyediakan secara cepat dan tepat. Variabel menggunakan instrumen Darwin dan Kunto (2014), Wiyanto (2016), Koesasi dan Latief (2017) yang disesuaikan dengan subjek penelitian saat ini. Pengukuran menggunakan skala likert dengan poin 1-4. Indikator variabel ini antara lain kecepatan dalam melayani anggota, kesediaan dalam membantu anggota, dan kesiapan dalam merespon permintaan anggota.

4. $\mathrm{X}_{4}$ Assurance adalah jaminan yang diberikan pegawai yakni teller kepada anggota dalam bentuk pengetahuan, sopan santun, dan kemampuan karyawan untuk menimbulkan keyakinan dan rasa percaya nasabah. Variabel ini menggunakan instrumen Wiharsih dan Efendi (2014), Koesasi dan Latief (2017), Wiyanto (2016) yang disesuaikan dengan subjek penelitian saat ini. Pengukuran menggunakan skala likert dengan poin 1-4. Indikator dalam variabel ini antara lain kemampuan dalam memberikan solusi dan masukan pada anggota, berpengetahuan luas dan berpengalaman, kemampuan beretika secara konsisten, dan kemampuan dalam merespon hal hal tertentu dari anggota.

5. $\mathrm{X}_{5}$. Empathy adalah kepedulian dan perhatian secara pribadi yang diberikan oleh teller kepada 
nasabah. Variabel menggunakan instrument yang dipakai oleh Darwin dan Kunto (2014), Koesasi dan Latief (2017) yang disesuaikan dengan subjek penelitian saat ini. Pengukuran menggunakan skala likert dengan poin 1-4. Indikator dalam variabel ini adalah memberi perhatian kepada anggota yang mengalami kendala, menjalin hubungan baik dengan anggota, dan dapat memahami apa yang anggota perlukan.

6. Y. Kepuasan Pelanggan menurut Gerson (2001:5) adalah terpenuhinya harapan seseoarang atas jasa atau produk yang digunakannya. Instrumen penelitian ini yang dipakai oleh Wiharsih dan Efendi (2014), Wiyanto (2016), Mustofa dan Siyamto (2015), Yulianti (2013), serta Koesasi dan Latief (2017) dan telah disesuaikan dengan subjek penelitian saat ini. Pengukuran memakai skala likert dengan poin 1-4. Indikator variabel ini adalah saya puas dengan kinerja dan kualitas pelayanan yang diberikan, saya puas dengan kecakapan dalam pelayanan yang diberikan, kepuasan produk yang ditawarkan, saya akan merekomendasikan BMT Polidana polines kepada orang lain, saya puas selama menjalin hubungan dengan BMT Polidana polines.

Model persamaan yang digunakan adalah model regresi linier berganda dengan SPSS 21. Persamaan model regresi yang digunakan dalam penelitian ini yaitu:

$Y=a+b_{1 \times 1}+b_{2 \times 2}+b_{3 \times 3}+b_{4 \times 4}+b_{5 \times 5}+e$

Dimana:

$$
\begin{array}{ll}
\mathrm{a} & =\text { Konstanta } \\
\mathrm{b} & =\text { slope } \\
\mathrm{X} 1 & =\text { Tangibles } \\
\mathrm{X} 2 & =\text { Reliability } \\
\mathrm{X} 3 & =\text { Responsiveness }
\end{array}
$$

$\begin{array}{ll}\mathrm{X} 4 & =\text { Assurance } \\ \mathrm{X} 5 & =\text { Empathy } \\ \mathrm{Y} & =\text { Kepuasan Nasabah } \\ \mathrm{e} & =\text { Error }\end{array}$

\section{Hasil Penelitian}

Hasil uji kualitas data menunjukkan semua variabel dalam penelitian ini dinyatakan valid untuk indikator yang digunakan sebagai alat ukur dan reliabel untuk semua pernyataan yang digunakan dalam penelitian ini, sesuai dengan nilai yang ditunjukkan pada tabel 3 dan 4 telah memenuhi kriteria pengujian validitas dan pengujian reliabilitas.

Tabel 3 Hasil Pengujian Validitas

\begin{tabular}{|c|l|c|c|c|}
\hline No & \multicolumn{1}{|c|}{ Variabel dan Indikator } & $r_{\text {tabel }}$ & $r_{\text {hitung }}$ & Keterangan \\
\hline 1 & Tangible $\left(\mathrm{X}_{1}\right)$ & & & \\
& Pernyataan 1 & 0,197 & 0,555 & Valid \\
& Pernyataan 2 & 0,197 & 0,522 & Valid \\
& Pernyataan 3 & 0,197 & 0,402 & Valid \\
& Pernyataan 4 & 0,197 & 0,543 & Valid \\
\hline 2 & Reliability $\left(\mathrm{X}_{2}\right)$ & & & \\
& Pernyataan 1 & 0,197 & 0,681 & Valid \\
& Pernyataan 2 & 0,197 & 0,668 & Valid \\
& Pernyataan 3 & 0,197 & 0,659 & Valid \\
\hline 3 & Responsiveness $\left(\mathrm{X}_{3}\right)$ & & & \\
& Pernyataan 1 & 0,197 & 0,496 & Valid \\
& Pernyataan 2 & 0,197 & 0,609 & Valid \\
& Pernyataan 3 & 0,197 & 0,613 & Valid \\
\hline
\end{tabular}




\begin{tabular}{|c|l|c|c|c|}
\hline 4 & Assurance $\left(\mathrm{X}_{4}\right)$ & 0,197 & 0,482 & Valid \\
& Pernyataan 1 & 0,197 & 0,657 & Valid \\
& Pernyataan 2 & 0,197 & 0,658 & Valid \\
& Pernyataan 3 & 0,197 & 0,629 & Valid \\
\hline 5 & Pernyataan 4 & & & \\
& Empathy $\left(\mathrm{X}_{5}\right)$ & 0,197 & 0,489 & Valid \\
& Pernyataan 1 & 0,197 & 0,618 & Valid \\
& Pernyataan 2 & 0,197 & 0,625 & Valid \\
\hline 6 & Pernyataan 3 & & & \\
& Kepuasan Nasabah $(\mathrm{Y})$ & 0,197 & 0,660 & Valid \\
& Pernyataan 1 & 0,197 & 0,448 & Valid \\
& Pernyataan 2 & 0,197 & 0,733 & Valid \\
& Pernyataan 3 & 0,197 & 0,443 & Valid \\
& Pernyataan 4 & 0,197 & 0,531 & Valid \\
\hline
\end{tabular}

Sumber : Data Primer yang Diolah

Tabel 4 Hasil Pengujian Reliabilitas

\begin{tabular}{|c|l|c|c|c|}
\hline No & \multicolumn{1}{|c|}{ Variabel } & $\begin{array}{c}\text { Nilai } \\
\text { Cronbach's Alpha }\end{array}$ & Kriteria & Keterangan \\
\hline 1 & Tangible $\left(\mathrm{X}_{1}\right)$ & 0,714 & 0,600 & Reliabel \\
\hline 2 & Reliability $\left(\mathrm{X}_{2}\right)$ & 0,816 & 0,600 & Reliabel \\
\hline 3 & Responsiveness $\left(\mathrm{X}_{3}\right)$ & 0,745 & 0,600 & Reliabel \\
\hline 4 & Assurance $\left(\mathrm{X}_{4}\right)$ & 0,791 & 0,600 & Reliabel \\
\hline 5 & Empathy $\left(\mathrm{X}_{5}\right)$ & 0,748 & 0,600 & Reliabel \\
\hline 6 & Kepuasan Nasabah $(\mathrm{Y})$ & 0,784 & 0,600 & Reliabel \\
\hline
\end{tabular}

Sumber : Data Primer yang Diolah

Hasil pengujian asumsi klasik yakni tabel 5 menunjukkan pengujian normalitas yang menghasilkan nilai kolmogorov-smirnov test sebesar 0,486 dengan nilai signifikansi sebesar 0,972 lebih dari 0,05 yang berarti data terdistribusi normal.

Tabel 5 Hasil Pengujian Normalitas

\begin{tabular}{|l|l|r|}
\hline \multicolumn{2}{|c|}{ One-Sample Kolmogorov-Smirnov Test } \\
\hline \multicolumn{2}{|c|}{} & Unstandardized Residual \\
\hline $\mathrm{N}$ & Mean & 100 \\
\cline { 2 - 3 } Normal Parametersa,b & Std. Deviation &, 0000000 \\
\hline \multirow{2}{*}{$\begin{array}{l}\text { Most Extreme } \\
\text { Differences }\end{array}$} & Absolute & 1,40298761 \\
\cline { 2 - 3 } & Positive &, 049 \\
\cline { 2 - 3 } & Negative &, 039 \\
\hline Kolmogorov-Smirnov Z &,- 049 \\
\hline Asymp. Sig. (2-tailed) &, 486 \\
\hline
\end{tabular}

Sumber: Data Primer yang Diolah 
Pengujian multikolinearitas dalam tabel 6 menunjukkan hasil masing-masing variabel mempunyai nilai tolerance lebih dari 0,10 dan VIF kurang dari 10 sehingga dapat disimpulkan data terbebas dari problem multiko.

\begin{tabular}{|l|c|c|}
\multicolumn{1}{|c|}{ Tabel 6 Hasil Pengujian Multikolonieritas } \\
\cline { 2 - 3 } \multicolumn{1}{|c|}{ Variabel } & \multicolumn{2}{c|}{ Collinearity Statistics } \\
\cline { 2 - 3 } & Tolerance & VIF \\
\hline Tangible &, 978 & 1,022 \\
\hline Reliability &, 616 & 1,623 \\
\hline Responsiveness &, 443 & 2,257 \\
\hline Assurance &, 909 & 1,100 \\
\hline Empathy &, 561 & 1,783 \\
\hline
\end{tabular}

Sumber : Data Primer yang Diolah

Pengujian durbin watson dalam tabel 7 memperlihatkan bahwa data tidak ada autokorelasi positif yang ditunjukkan dengan nilai du (upper) 1,780 dan nilai dl (lower) 1,571. Dari data tersebut terdapat nilai $0<1,497<1,571$.

Tabel 7 Hasil Pengujian Durbin Watson

\begin{tabular}{|l|c|r|r|r|r|}
\hline \multicolumn{7}{|c|}{ Model Summary } \\
\hline Model & $\mathrm{R}$ & $\mathrm{R}$ Square & $\begin{array}{c}\text { Adjusted R } \\
\text { Square }\end{array}$ & $\begin{array}{c}\text { Std. Error of the } \\
\text { Estimate }\end{array}$ & Durbin-Watson \\
\hline 1 &, $686^{\mathrm{a}}$ &, 470 &, 442 & 1,4398 & 1,497 \\
\hline
\end{tabular}

Sumber : Data Primer yang Diolah

Hasil pengujian heteroskedastisitas yang ditunjukkan pada gambar 2, terlihat banyak titik menyebar dengan acak dan tersebar disekeliling maka dikatakan tidak terjadi heteroskedastisitas.

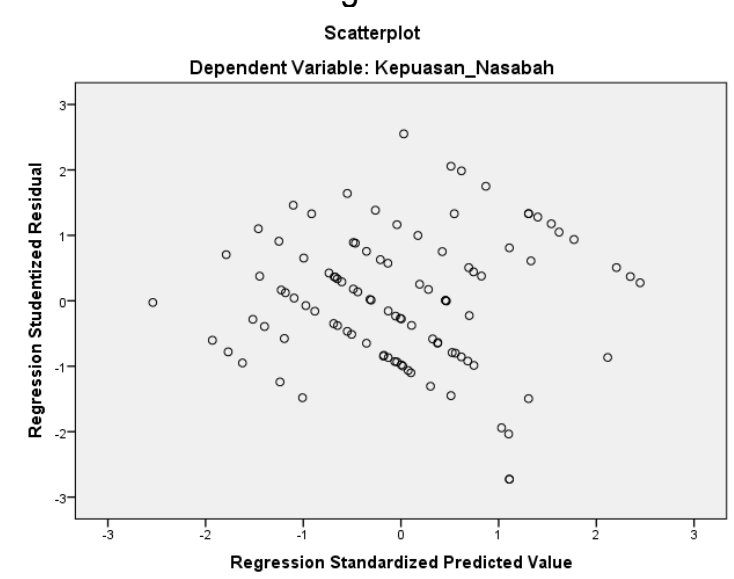

Sumber : Data Primer yang Diolah

Gambar 2 Hasil Pengujian Heteroskedastisitas

Hasil pengujian $F$ (model) pada tabel 8 menunjukkan hasil $F_{\text {hitung }}$ sebesar 16,683 lebih besar dari $F_{\text {tabel }} 2,37$. Hal ini menunjukkan bahwa model yang diuji dalam penelitian ini layak untuk dilakukan uji hipotesis. 
Tabel 8 Hasil Uji F

\begin{tabular}{|c|l|r|r|r|r|r|}
\hline \multicolumn{2}{|c|}{ ANOVA $^{\text {a }}$} \\
\hline \multicolumn{2}{|c|}{ Model } & $\begin{array}{c}\text { Sum of } \\
\text { Squares }\end{array}$ & df & $\begin{array}{c}\text { Mean } \\
\text { Square }\end{array}$ & \multicolumn{1}{c|}{ F } & \multicolumn{1}{c|}{ Sig. } \\
\hline \multirow{2}{*}{1} & Regression & 172,921 & 5 & 34,584 & 16,683 &, $000^{\mathrm{b}}$ \\
\cline { 2 - 8 } & Residual & 194,869 & 94 & 2,073 & & \\
\cline { 2 - 8 } & Total & 367,790 & 99 & & & \\
\hline
\end{tabular}

Sumber: Data Primer yang Diolah

Hasil Uji koefisien determinasi dalam tabel 9 menunjukkan hasil bahwa koefisien determinasi (Adjusted $R$ Square) 0,442 atau 44,2\% kepuasan nasabah dalam menabung pada BMT Polidana Polines dipengaruhi oleh kualitas pelayanan dengan faktor tangibles, reliability, responsiveness, assurance, dan empathy, sedangkan sisanya 55,8\% kepuasan nasabah dalam menabung pada BMT Polidana Polines dipengaruhi oleh faktor lain yang tidak termasuk dalam penelitian.

Tabel 9 Hasil Pengujian Koefisien Determinasi

\begin{tabular}{|l|l|r|r|r|r|}
\hline \multicolumn{6}{|c|}{ Model Summary $^{\text {Adjusted R }}$} \\
\hline Model & $\mathrm{R}$ & R Square & $\begin{array}{c}\text { Std. Error of the } \\
\text { Square }\end{array}$ & $\begin{array}{c}\text { Estimate } \\
\text { Durbin-Watson }\end{array}$ \\
\hline 1 &, $686 \mathrm{a}$ &, 470 &, 442 & 1,4398 & 1,497 \\
\hline
\end{tabular}

Sumber: Data Primer yang Diolah

Hasil pengujian $\mathrm{t}$ (Parsial) pada tabel 10 menunjukkan pengaruh yang signifikan pada variabel kualitas layanan yakni tangibles, reliability, responsiveness, assurance terhadap kepuasan nasabah dalam menabung pada BMT Polidana. Sedangkan variabel empathy tidak berpengaruh signifikan. maka dapat dikatakan hipotesis 1 sampai 4 diterima dengan nilai signifikansi berada dibawah 0,05, sedangkan hipotesis 5 ditolak karena nilai signifikasi diatas 0,05 .

Tabel 10 Hasil Uji $t$ (Parsial)

\begin{tabular}{|c|c|c|c|c|c|c|}
\hline \multicolumn{7}{|c|}{ Coefficients $^{a}$} \\
\hline \multirow{2}{*}{\multicolumn{2}{|c|}{ Model }} & \multicolumn{2}{|c|}{$\begin{array}{l}\text { Unstandardized } \\
\text { Coefficients }\end{array}$} & \multirow{2}{*}{$\begin{array}{c}\text { Standardized } \\
\text { Coefficients } \\
\text { Beta } \\
\end{array}$} & \multirow[t]{2}{*}{$\mathrm{t}$} & \multirow[t]{2}{*}{ Sig. } \\
\hline & & $B$ & Std. Error & & & \\
\hline \multirow[t]{6}{*}{1} & (Constant) & 4,310 & 1,917 & & 2,248 & 027 \\
\hline & Tangible & .731 & .090 & .618 & 8,139 & .000 \\
\hline & Reliability &, 366 & ,112 & ,312 & 3,263 &, 002 \\
\hline & Responsiveness &,- 380 & ,151 &,- 283 & $-2,509$ &, 014 \\
\hline & Assurance & 259 & 099 & 206 & 2,612 & 010 \\
\hline & Empathy & -.045 & 149 &,- 030 &,- 299 & 766 \\
\hline
\end{tabular}

Sumber: Data Primer yang Diolah

Variabel dimensi tangibles memiliki pengaruh yang signifikan terhadap kepuasan nasabah dalam menyimpan dananya di BMT Polidana Polines sehingga sesuai dengan hipotesis 1 yang diajukan. Hipotesis 1 ini dinyatakan diterima dan mendukung oleh penelitian terdahulu yaitu dalam penelitian Koesasi dan Latief (2017), Lumempow dkk. (2015), Rosita (2015). Dalam hal ini BMT Polidana Polines, telah memberikan pelayanan yang baik kepada nasabah, dalam penyediaan sarana prasaran, penampilan pegawai yang baik dan rapi, suasana ruangan yang nyaman untuk melayani nasabah sehingga nasabah senang dengan tangibles yang ditunjukkan oleh BMT Polidana kepada 
para nasabahnya dengan memperlihatkan ekspresi bahagia dan kenyamanan. Variabel dimensi reliability (keandalan) memiliki pengaruh yang signifikan terhadap kepuasan anggota dalam menyimpan dananya di BMT Polidana Polines. Hipotesis 2 ini dinyatakan diterima dan mendukung oleh penelitian terdahulu yaitu penelitian Koesasi dan Latief (2017), Lumempow dkk. (2015), Rosita (2015). Hal ini menunjukkan BMT Polidana Polines telah mampu melayani kebutuhan nasabah dengan baik secara akurat dan terpercaya, mampu menangani masalah yang dihadapi nasabah, dan ketepatan informasi yang diberikan sehingga pegawai frontliner yakni teller dapat diandalkan dalam menangani masalah dan keluhan para nasabah. Hal tersebut dapat membawa pengaruh yang baik untuk kepuasan nasabah atas kepercayaan yang diberikan oleh BMT Polidana untuk dapat mengelola dana yang telah diberikan dari para nasabah. BMT Polidana berupaya meningkatkan kepercayaan yang telah diamanahkan nasabah kepadanya. Variabel dimensi responsiveness (daya tanggap) mempunyai pengaruh signifikan terhadap kepuasan anggota dalam menyimpan dananya di BMT Polidana Polines. Hipotesis 3 ini dinyatakan diterima dan mendukung penelitian terdahulu yaitu penelitian Koesasi dan Latief (2017), Lumempow dkk. (2015), Rosita (2015). Dalam hal ini BMT Polidana Polines telah memberikan pelayanan yang baik, hal ini dilihat dari kemampuan merespon kebutuhan nasabah dengan memberikan pelayanan secara cepat dan tanggap, kesediaan dalam membantu nasabah, dan siap merespon permintaan nasabah. Respon yang cepat akan sangat membantu nasabah dalam menjawab semua kebutuhan nasabah. Dengan kecepatan respon yang diberikan akan memberikan nilai tambah di mata nasabah sehingga meningkatkan kepuasan nasabah yang dapat membawa pengaruh positif terhadap kepuasan nasabah. Variabel dimensi assurance (jaminan) memiliki pengaruh signifikan terhadap kepuasan anggota dalam menabung pada BMT Polidana Polines. Hipotesis 4 ini dinyatakan diterima dan mendukung penelitian terdahulu yaitu penelitian Koesasi dan Latief (2017), Lumempow dkk. (2015), Rosita (2015), Wiharsih dan Efendi (2014). Dalam hal ini BMT Polidana Polines telah memberikan pelayanan yang baik kepada nasabah, dilihat dari kemampuan memberikan saran dan solusi kepada nasabah, berpengetahuan luas, beretika secara konsisten, dan mampu merespon atas ketidaktahuan nasabah. Hal tersebut memberikan pengaruh yang baik terhadap kepuasan nasabah. Jaminan yang diberikan BMT Polidana membuat nasabah aman dalam menyimpan dananya di BMT untuk dapat dikelola sesuai dengan ketentuan dan kebijakan BMT Polidana. Variabel dimensi empathy (empati) tidak mempunyai pengaruh signifikan terhadap kepuasan anggota dalam menyimpan dananya pada BMT Polidana Polines. Hipotesis 5 ini dinyatakan ditolak dan tidak mendukung penelitian terdahulu yaitu penelitian Lumempow dkk. (2015), Rosita (2015), Wiharsih dan Efendi (2014) sedangkan penelitian Koesasi dan Latief (2017) mendukung hasil penelitian ini. Dalam hal ini BMT Polidana Polines belum memberikan perhatian dalam bentuk pelayanan yang baik dalam memahami kebutuhan nasabah. Empathy merupakan bentuk rasa peduli dan perhatian yang timbul dari pribadi seseorang dalam hal ini frontliner yakni teller yang diberikan kepada pelanggan selama melayani pelanggan. Dalam bekerja sikap yang harus dilakukan adalah menekankan pada profesionalitas, sehingga tidak menonjolkan rasa peduli dan perhatian yang diberikan secara pribadi kepada para nasabah. BMT Polidana dalam melayani nasabah selalu mengedapankan profesionalitas dalam bekerja sehingga hal ini akan meminimalkan konflik kepentingan yang dapat terjadi antara nasabah dengan pihak pengelola BMT Polidana.

\section{Penutup}

Penelitian ini menguji pengaruh kualitas pelayanan yang terdiri dari tangibles, reliability, responsiveness, assurance, dan empathy terhadap kepuasan nasabah pada BMT Polidana Polines. Hasil pengujian menunjukkan tangibles, reliability, responsiveness, dan assurance memiliki pengaruh 
yang signifikan, sedangkan empathy tidak memiliki pengaruh yang signifikan terhadap kepuasan nasabah dalam menabung pada BMT Polidana Polines.

Dalam meningkatkan kualitas layanan, BMT Polidana terutama harus mampu meningkatkan pelayanan kepada nasabah dengan terus meningkatkan performa, keandalan, responsif serta garansi, dan empati sehingga nasabah senang dan percaya untuk memanfaatkan BMT Polidana sebagai wadah dalam menyimpan dananya. Untuk penelitian selanjutnya diharapkan dapat mengembangan dimensi lain dari kualitas layanan serta mengembangkan alat analisis lain untuk menganalisis data penelitian.

\section{Daftar Pustaka}

Darwin, S. dan Kunto, Y.S. (2014). Analisis Pengaruh Kualitas Layanan Terhadap Loyalitas Pelanggan Dengan Kepuasan dan Kepercayaan Pelanggan Sebagai Variabel Intervening Pada Asuransi Jiwa Manulife Indonesia - Surabaya. Jurnal Manajemen Pemasaran Petra, 2(1), 1-12.

Gerson, R.F., Widyaningrum, H. (2001). Mengukur Kepuasan Pelanggan: Panduan Menciptakan Pelayanan Murni. Jakarta: Lembaga Manajemen PPM.

Ghozali, I. (2018). Aplikasi Analisis Multivariate dengan Program SPSS. Semarang: Badan Penerbit Universitas Diponegoro.

Guru Ekonomi. (2020). Baitul Maal Wat Tamwil. (https://sarjanaekonomi.co.id/pengertian-bmt/. Webpage., 21 Juli 2020)

Kasmir. (2007). Dasar-Dasar Perbankan. Jakarta: PT Raja Grafindo Persada.

Koesasi, M. dan Latief, M.A. (2017). Analisis Pengaruh Kualitas Pelayanan Terhadap Kepuasan Nasabah Pada Unit Usaha Syariah (UUS) PT. Bank Tabungan Negara (Persero), Tbk. Kantor Cabang Syariah Balikpapan. Jurnal Akuntansi Manajemen Madani, 1(1), 91-114.

Kuswanto, Adi. (2009). Pengaruh Kualitas Layanan Terhadap Tingkat Kepuasan Nasabah. Jurnal Ekonomi Bisnis, 14(2), 125-134.

Lumempow, N.R., Mandey, S., Rotinsulu, J.J. (2015). Analisis Faktor-Faktor Kualitas Pelayanan Terhadap Kepuasan Nasabah Pada PT. Bank Mandiri. Tbk Cabang Bahu Mall Manado. Jurnal EMBA. 3(3), September 2015, 1275-1286.

Mustofa, U.Z. dan Siyamto, Y. (2015). Pengaruh Kualitas Jasa Terhadap Kepuasan Nasabah Pada Bank Umum Syariah di Surakarta. Jurnal IImiah Ekonomi Islam, 1(2), 94-105.

Panjaitan, J.E., Yuliati, A.L. (2016). Pengaruh Kualitas Pelayanan Terhadap Kepuasan Pelanggan Pada JNE Cabang Bandung. DeReMa Jurnal Manajemen, 11(2), September 2016, 265-289.

Puung, F.K., Fudholi, A., Dharmmesta, B.S. (2014). Analisis Pengaruh Kualitas Pelayanan Pada Kepuasan dan Loyalitas Pelanggan Di Salon dan Spa. Jurnal Manajemen dan Pelayanan Farmasi, 4(2), 105-110.

Rangkuti, F. (2002). Measuring Customer Satisfaction. Jakarta: Gramedia Pustaka Utama.

Rosita, R. (2015). Pengaruh Kualitas Pelayanan Terhadap Kepuasan Nasabah BNI, BRI, Bank Mandiri dan BCA di Bekasi. E-Journal WIDYA Ekonomika, 1(1), 51-57.

Sugiyono. (2012). Memahami Penelitian Kualitatif. Bandung: Alfabeta.

Sulistyawati, N.M.A., Seminari, N.K. (2015). Pengaruh Kualitas Pelayanan Terhadap Kepuasan Pelanggan Restoran Indus Ubud Gianyar. E-Jurnal Manajemen Unud, 4(8), 2318-2332.

Wiharsih, N.E., Efendi. (2014). Kepuasan Pelanggan Terhadap Layanan Frontline. Jurnal Manajemen, 11(2), 83-91.

Wiyanto. (2016). Analisis Pengaruh Kualitas Pelayanan Terhadap Kepuasan Tinggi dan Rendah Nasabah di Bank Syariah Mandiri Cabang Salatiga. MUQTASID Jurnal Ekonomi dan Perbankkan Syariah, 7(2), 117-135. 
Yulianti, F. (2013). Pengaruh Kualitas Layanan Terhadap Kepuasan Nasabah Tabungan Pada Bank Panin TBK KCP A. Yani Banjarmasin. SPREAD Jurnal IImiah Bisnis dan Keuangan, 3(2), 87100. 